\title{
Recovery of genetic diversity in threatened plants through use of germinated seeds from herbarium specimens
}

\section{AUTHOR(S):}

Nakahama, Naoyuki; Hirasawa, Yuki; Minato, Tsubasa; Hasegawa, Masahiro; Isagi, Yuji; Shiga, Takashi

\section{CITATION:}

Nakahama, Naoyuki ... [et al]. Recovery of genetic diversity in threatened plants through use of germinated seeds from herbarium specimens. Plant Ecology 2015, 216(12): 16351647

\section{ISSUE DATE:}

2015-12

URL:

http://hdl.handle.net/2433/207704

\section{RIGHT:}

The final publication is available at Springer via http://dx.doi.org/10.1007/s11258-015-0547-8: The full-text file will be made open to the public on 1 December 2016 in accordance with publisher's 'Terms and Conditions for Self-Archiving', この論文は出版社版でありません。引用の際には出版社版をご確認ご利用ください。; This is not the published version. Please cite only the published version. 
1 Recovery of genetic diversity in threatened plants through use of germinated seeds from herbarium

2 specimens

3

6

7

8

9

10

Naoyuki NAKAHAMA ${ }^{1}$, Yuki HIRASAWA², Tsubasa MINATO ${ }^{3}$, Masahiro HASEGAWA ${ }^{4}$, Yuji ISAGI ${ }^{1}$, Takashi SHIGA 2,3

${ }^{1}$ Graduate School of Agriculture, Kyoto University, Oiwake-cho, Kitashirakawa, Sakyo-ku, Kyoto 606-8502, Japan

${ }^{2}$ Graduate School of Education, Niigata University, 8050, Ikarashi2-no-cho, Nishi-ku, Niigata 950-2181, Japan

${ }^{3}$ Faculty of Education, Niigata University, 8050, Ikarashi2-no-cho, Nishi-ku, Niigata 9502181, Japan

${ }^{4}$ Osaka Museum of Natural History. Nagai Park 1-23, Higashisumiyoshi-ku, Osaka 546-0034, Japan

Corresponding author: Naoyuki Nakahama

E-mail: nakahama.naoyuki.68r@st.kyoto-u.ac.jp, The Graduate School of Agriculture, Kyoto University, Kitashirakawa Oiwake-cho, Sakyo-ku Kyoto 606-8502, Japan.

Tel: +81 75753 6129, Fax: 81757536129

5003 words (Abstract 195 words) 


\section{Abstract}

24 The reintroduction of ex situ conserved individuals is an important approach for conserving threatened plants and reducing extinction risk. In this study, we elucidated the effects on the genetic diversity of wild populations of Vincetoxicum pycnostelma Kitag. [= Cynanchum paniculatum (Bunge) Kitag.] by modelling the genetic consequences of reintroducing plants using the germinated seeds of herbarium specimens. This semi-natural grassland herb is threatened in Japan. First, we tested the germinability of seeds from herbarium specimens collected from nine sites in Kinki and Tokai districts, Japan (one specimen per site, total 206 seeds). Next, we analysed the genetic diversity and structure of germinated seedlings and the current wild individuals using nine polymorphic microsatellite markers. Germination was observed for 38 seeds (18.4\%) from four specimens collected 3-18 years prior to the study. Although the genetic diversity of the specimens' seeds was lower than that of the wild population because of the small sample size, the seedlings from specimens taken from three sites had unique alleles that did not exist in the wild populations. recovering the genetic diversity in threatened wild plant populations.

39 Keyword: threatened plants, genetic diversity recovery, germination test, microsatellite, reintroduction 
Many species worldwide face an extinction crisis because of the destruction and fragmentation of habitats as a result of human activities (Ceballos and Ehrlich 2002; Hooper et al. 2005; Aguilar et al. 2006). To conserve the populations of threatened species, it is crucial to maintain not only population size and habitat but also genetic diversity for preventing the decline in reproductive success owing to inbreeding depression, which would escalate the extinction risk (Keller and Waller 2002; Mattila et al. 2012; Palomares et al. 2012). Furthermore, a loss of genetic diversity would compromise their adaptive potential, particularly in the face of concerns pertaining to climate change (Blows and Hoffmann 2005; Willi et al. 2006).

Although the conservation of natural habitat is critical for conserving ecological interactions, in situ and ex situ conservation is also appropriate for safeguarding individual species against extinction in the wild. For example, use of soil seed bank is an in situ natural resource for the reproduction of plants that is effective for the restoration of genetic diversity (Uesugi et al. 2007; Zaghloul et al. 2013). On the other hand, the primary purpose of ex situ conservation is to maintain wild species outside their natural habitat so that species recovery and reintroduction can be attempted if the wild populations severely decline or become extinct. It is well known that preserved seeds are useful as ex situ populations (Honnay et al. 2008; Frankham et al. 2009; Hoban and Schlarbaum 2014). The reintroduction of many individuals germinated from preserved seeds also allows the recovery of population size and genetic diversity (Honnay et al. 2008; Guerrant et al. 2014; Hoban and Schlarbaum 2014). Thus, projects to preserve the seeds of many plants are used worldwide and comprise an efficient method for plant reintroduction and conservation (Schoen and Brown 2001; Guerrant et al. 2014; Hoban and Schlarbaum 2014). For example, the 'Millennium 
64

65

66

67

68

69

Seed Bank Project' of the Royal Botanic Gardens, Kew, the 'Svalbard Global Seed Vault' and many other botanical gardens store wild and cultivated plant seeds as a resource for future use in conservation translocations and crop development (Schoen and Brown 2001; Van Slageren 2003; Qvenild 2008; Alsos et al. 2013).

However, re-establishment of the seeds collected in the past has risks pertaining to inbreeding and inbreeding depression if the sources are restricted or population size is small (Frankel and Soulé 1981; Schoen and Brown 2001). In addition, reintroduced individuals collected from remote habitats would also have reduced fitness because of local adaptation (Becker et al. 2006; Leimu and Fischer 2008; Hereford 2009). Furthermore, reintroduced individuals that are genetically distinct from a wild population would not only have a risk of outbreeding depression (Montalvo and Ellstrand 2001; Huff et al. 2011), but would also lead to the loss of the local genetic identity of the native population (Gottelli et al. 1994; Milián-García et al. 2014). Accordingly, to conserve threatened plants by reintroducing individuals from preserved seeds, it is very important to collect many seeds from widely dispersed populations (Falk and Holsinger 1991; Hoban and Schlarbaum 2014). However, collecting seed resources of threatened or locally extinct species from wild populations may be difficult, although seed banking projects throughout the world have been recently constructed and followed the protocols to ensure the maintenance of genetic diversity (León-Lobos et al. 2012; Guerrant et al. 2014; Hoban and Schlarbaum, 2014). Herbarium specimens in museums can retain viable and germinable diaspores (Windham et al. 1986; Bowles et al. 1993; Lledó et al. 1996; Magrini et al. 2010; Magrini 2011; Bewley et al. 2013; Shiga 2013); therefore, they have potential as a reintroduction resource. Furthermore, the viable diaspores in herbaria specimens are also useful for the conservation of threatened local populations in each plant species because presumably the 
specimens are collected from these populations. Despite the potential use of herbarium specimens' seeds, the effect of reintroduced seeds on the restoration of genetic diversity has not been studied, and it is unknown whether genetic diversity now lost in wild populations can be found in herbarium collections. Vincetoxicum pycnostelma Kitag. [= Cynanchum paniculatum (Bunge) Kitag.] (Fig. 1a), subfamily Asclepiadoideae of Apocynaceae, is a perennial herb that grows in semi-natural grasslands in Japan, Korea, China, Mongolia and Russia (Yamazaki 1993; Wu and Raven 1995; Flora of Korea Editorial Committee 2007). Although this species was common a few decades ago, its populations have rapidly declined because of land-use changes in semi-natural grasslands in Japan (Environment Agency of Japan 2000; Uematsu et al. 2010). It is estimated that the extinction probability after 100 years is 96\% (Environment Agency of Japan 2000). The species is categorized as 'near threatened' in the Japanese Red List (Ministry of the Environment Government of Japan 2012). Many other native herbaceous plants have also experienced a rapid decline in semi-natural grasslands (Koyanagi and Furukawa 2013); hence V. pycnostelma is a prime example of these rare and threatened species. In this study, we examined the germinability of seeds from herbarium specimens of $V$. pycnostelma and we assessed the effect on the genetic diversity and structure of the wild populations by modelling the reintroduction of germinated seeds. We also discuss suitable methods for collecting and managing herbarium specimens' seeds at museums that are to be used for conserving not only threatened plants but also the local populations in each species.

107 Selection of herbarium specimens 
108 Seeds were collected from the herbarium of the Osaka Museum of Natural History, Japan (Figs. 1a,

109 b). The museum was established in 1974, and the herbarium preserves more than 270,000 vascular

110 plant specimens (Osaka Museum of Natural History 2012). In this herbarium, insect control involved

111 naphthalene application and fumigation with carbon disulphide; the room temperature was not

112 controlled until 2000. However, since 2001, integrated insect control has been performed by

113 applying naphthalene and freezing treatments and the room conditions have been controlled at $20^{\circ} \mathrm{C}$

114 and 50\% humidity. In the herbarium, 206 seeds from nine specimens with mature fruits (one

115 specimen per site) from Kinki and Tokai districts, Japan, had been collected (Fig. 2). The ages of the

116 nine stored specimens were from 4 to 62 years (Table 1). Seeds were collected from only one fruit

117 per specimen. After the germination test, specimens of the seedlings or seeds were mounted and

118 donated to the Osaka Museum of Natural History with annotation cards.

120 Germination test of herbarium specimens’ seeds

121 Germination of the herbarium specimens’ seeds was tested using the screening test system

122 (Washitani 1987) under a 12/12-h photoperiod and two temperature regimes: 1) a gradually

123 increasing temperature regime from $4^{\circ} \mathrm{C}$ to $36^{\circ} \mathrm{C}$ at intervals of $4^{\circ} \mathrm{C}$ (IT) and 2) a gradually

124 decreasing temperature regime from $36^{\circ} \mathrm{C}$ to $4^{\circ} \mathrm{C}$ at intervals of $4^{\circ} \mathrm{C}$ (DT). The two treatments were

125 conducted because the preservation condition in the herbarium may have affected the dormancy of

126 the specimens' seeds, and it was predicted that a cold stratification treatment would be required to

127 break the seed dormancy of V. pycnotelma (Zhou et al. 2003). Considering that growth rate increases

128 with temperature, the duration of the higher temperature treatment was less than the duration of the

129 lower temperature treatment (Table S1). After reaching the final temperature in each regime, these 
seeds were incubated at $25^{\circ} \mathrm{C}$ (DT, 5 days) or treated at alternating temperatures of $12^{\circ} \mathrm{C}$ and $25^{\circ} \mathrm{C}$ at

131 24-h intervals (IT, total 5 days). The number of germinated seedlings was counted when the

132 temperatures were changed, and the seedlings were moved to an incubator at $25^{\circ} \mathrm{C}$ to determine whether they would grow normally. For microsatellite analysis, we selected well-growing plants among 32 samples of 38 seedlings obtained from four specimen sheets. The germination test was conducted in June 2012 (Site i) and May 2013 (Sites a-h; Table 1). examine their viability (Cottrell 1947; Elias et al. 2012). The seeds were cut and stained for $48 \mathrm{~h}$ in the dark with $1 \%$ tetrazolium solution, and seeds that stained red were defined as viable.

140 Sampling and microsatellite analysis

141 In 2012 and 2013, leaf samples from 131 adult individuals were collected from sites same as those

142 from where the herbarium specimens had been collected (Figs. 1c and 2). The samples were used to

143 estimate the genetic diversity among the extant populations (Table 2). At all sites, we

144 comprehensively collected samples from each entire patch. Because V. pycnotelma at Site e was

145 locally extinct, we collected leaf samples from a neighbouring population located one kilometre 146 away. The number of individuals was counted at each site.

147 Genomic DNA was extracted using a modified cetyltrimethylammonium bromide method

148 (Milligan 1992). The genotypes of each individual, including wild populations and specimens'

149 seedlings, were characterized at nine microsatellite loci. Seven of the nine loci were characterized by

150 Nakahama et al. (2012): Vpy002, Vpy006, Vpy012, Vpy013, Vpy16, Vpy018 and Vpy022. Two of the

151 nine loci were developed by Nakahama et al. (unpublished data): Vpy025 (GenBank accession 
152

153

154

155

156

157

158

159

160

161

162

number: AB948217) and Vpy031 (GenBank accession number: AB948218). Polymerase chain reaction (PCR) amplifications, except for those of Vpy025 and Vpy031, were performed following the standard protocol of the Qiagen Multiplex PCR kit (Qiagen) with a final reaction volume of $5 \mu \mathrm{L}$, which contained 16 ng extracted DNA, $2.5 \mu \mathrm{L}$ of $2 \times$ Multiplex Master Mix and $0.2 \mu \mathrm{M}$ of each multiplexed primer. For Vpy025 and Vpy031, the forward primer was synthesized with the M13 tag sequence (Vpy025 5'-CACGACGTTGTAAAACGAC-3', Vpy031 5'-TGTGGAATTGTGAGCGG-3'; Boutin-Ganache et al. 2001). The PCR mixtures of Vpy025 and Vpy031 had a final volume of $5 \mu \mathrm{L}$, which included $16 \mathrm{ng}$ extracted DNA, $2.5 \mu \mathrm{L}$ of Multiplex PCR Master Mix, $0.01 \mu \mathrm{M}$ forward primer, $0.2 \mu \mathrm{M}$ reverse primer and $0.1 \mu \mathrm{M}$ M13 fluorescent primer. The PCR amplifications of all loci were carried out using a GeneAmp PCR System 2700 thermal cycler (Applied Biosystems, Tokyo, Japan) using the following conditions: initial denaturation at $95^{\circ} \mathrm{C}$ for $15 \mathrm{~min}$, followed by 25 cycles of $30 \mathrm{~s}$ at $94^{\circ} \mathrm{C}, 1.5 \mathrm{~min}$ at $57^{\circ} \mathrm{C}$ and $1 \mathrm{~min}$ at $72^{\circ} \mathrm{C}$, and a final extension for $30 \mathrm{~min}$ at $60^{\circ} \mathrm{C}$. The PCR product size was measured using an ABI PRISM 3130 Genetic Analyzer (Applied Biosystems) and GeneMapper ver. 4.1 (Applied Biosystems).

Statistical analysis of the genetic diversity and structure

Genetic diversity was evaluated for the specimens' seedlings, the wild populations and the hypothetical mixed populations, which comprised a hypothetical mixing of the specimens' seedlings and each corresponding wild population. The genetic diversity was evaluated in terms of the following: average number of alleles per locus, allelic richness (El Mousadik and Petit 1996), summed number of rare alleles with frequencies less than $5 \%$ among the total population, expected heterozygosity, observed heterozygosity and inbreeding coefficient. We also evaluated the summed 
174 number of unique alleles that were only present in specimens' seedlings from each site. All of these

175 parameters, except allelic richness summed number of rare and unique alleles, were calculated using

176 GenAlEx version 6.41 (Peakall and Smouse 2006). Allelic richness, deviation from Hardy-Weinberg

177 equilibrium and the linkage disequilibrium between loci were also determined using FSTAT ver.

178 2.9.3 software (Goudet 2001). The significances of the heterozygosity excess and deficit values were

179 tested by comparison with the 95\% confidence intervals derived from 108,000 randomizations.

180 We evaluated the genetic relationships between the wild populations at all sites using Bayesian

181 clustering with STRUCTURE ver. 2.3.4. (Pritchard et al. 2010), which assigns individuals into $K$

182 clusters. The population structure was simulated with the values of $K=1-8$ under an admixture

183 model and the correlated allele frequency model (Hubisz et al. 2009). All runs involved one million

184 Markov chain Monte Carlo iterations after a burn-in period of one million iterations. Twenty runs

185 were performed for each value of $K$. The $F$ value, the estimated amount of genetic drift between each

186 cluster and a common ancestral population and the expected heterozygosity were calculated. The

187 number of clusters was determined by comparing the mean values and the variability of log

188 likelihoods for each run. To select the optimal value of $K$, STRUCTURE HARVESTER was used

189 (Earl and vonHoldt 2012). We also evaluated genetic relationships between the wild populations and

190 specimens' seedlings at each site by the same method.

191 To evaluate genetic differentiation between specimens' seedlings and wild populations for each

192 site at the individual level, we calculated pairwise co-dominant genotypic distances (Smouse and

193 Peakall 1999) between all specimens’ seedlings and wild individuals from all sites. We also

194 performed principal co-ordinates analysis (PCoA) using GenAlEx version 6.41 (Peakall and Smouse 195 2006). 


\section{Results}

198 Germination and viability of herbarium specimens’ seeds

199 A total of 38 seeds, representing four herbarium specimens, were germinated out of a total of 206

200 seeds (Fig. 1d and Table 1). The germination percentage for seeds from each specimen ranged from

$2010 \%$ to $56.5 \%$, with an average of $18.4 \%$. The oldest germinated specimens' seeds were collected 18

202 years prior to the study. Under the IT and DT conditions, seed germination from two and four

203 specimens were observed, respectively. Each $18.4 \%$ of the seeds germinated in both conditions.

204 Furthermore, 3.0\% of ungerminated seeds were confirmed to be viable according to the tetrazolium

205 dye test (Table 1). The viable seeds were collected from three herbarium specimens, which were

206 collected 9 to 18 years prior to the study. The ungerminated viable seeds were confirmed only in the

207 IT condition.

208

209 Genetic diversity of seedlings from herbarium specimens, wild populations and hypothetical mixed

210 populations

211 There was no evidence for large allele dropouts or null alleles in the data set. The numbers of alleles,

212 the allelic richness and the expected heterozygosity of herbarium specimens' seedlings was

213 considerably lower than those of the wild populations because their allele frequencies were

214 dominated by a few alleles, although the observed heterozygosity of the seedlings was similar

215 between wild populations and specimens seedlings at all sites. At Sites e, g and i, the number of

216 alleles of hypothetical mixed populations were higher than those of the wild populations because one

217 to three unique alleles existed only in the seedlings. The allelic richness of the hypothetical mixed 
218 populations was higher than that of the wild populations only at Site e. Although rare alleles were

219 much more common in the wild populations than in the seedlings at all sites, the seedlings had some rare alleles at all sites. Unique alleles in the specimens' seedlings were found at the three sites except

Site d. At Sites e and i, the expected heterozygosity of the hypothetical mixed populations was more than that of the wild populations. The inbreeding coefficient of the seedlings ranged from -0.767 to -0.205 , whereas that of the seedlings at Site i indicated significant heterozygosity excess (Table 2). On the other hand, no wild populations exhibited significant heterozygosity excesses. Significant linkage disequilibrium occurred at Site g for only one pair of loci (Vpy002/Vpy013; $P<0.05)$.

Genetic differentiation and structure of herbarium specimens’ seedlings and wild populations

The STRUCTURE analysis indicates that the wild populations were divided into distinct genetic clusters (Fig. 3a). The $\Delta K$ value representing the hierarchical approach for the STRUCTURE analysis was clearly the highest at $K=2$ (Fig. S1a). In addition, the variance of log likelihood between runs was low and the $\Delta K$ value was high at $K=3$ (Fig. S1a). Therefore, $K=3$ also yielded meaningful results. Thus, the results obtained with $K=2$ and $K=3$ are shown (Fig. 3a). When $K=2$, the individuals were divided into two clusters. The wild populations at Sites d, e and i were assigned to cluster I, and the wild population at Site g was assigned to cluster II. The F value of cluster I was higher than that of cluster II, and the expected heterozygosity of clusters I and II were 0.780 and 0.747, respectively (Fig. 3a). When $K=3$, cluster I from the $K=2$ analysis was divided into two clusters. The wild population at Site g was assigned to cluster II and those at Sites e and i were assigned to cluster III. The $F$ value of cluster III was lower than that of cluster I and II, and the expected heterozygosity of cluster I, II and III were $0.743,0.742$ and 0.781 , respectively (Fig. 3a). 
240 The wild populations and specimens’ seedlings were also divided into distinct genetic clusters (Fig.

$2413 \mathrm{~b})$. The $\Delta K$ value representing the hierarchical approach for the STRUCTURE analysis was clearly

242 highest at $K=3$ (Fig. S1b). Thus, $K=3$ was the uppermost hierarchical level of the genetic structure.

243 In addition, the variance of log likelihood between runs was low and the $\Delta K$ value was high at $K=4$

244 (Fig. S1b). Therefore, $K=4$ also yielded meaningful results. Thus, the results obtained with $K=3$ and $K=4$ are shown (Fig. 3b). When $K=3$, the individuals were clearly divided into three clusters. The wild population and herbarium specimens' seedlings at Site $d$ and the seedlings at Site e were assigned to cluster I. The wild populations at Sites e, g and i were assigned to cluster II. The seedlings at Sites g and i were assigned to cluster III. The $F$ values of cluster I and III were higher than that of cluster II, and the expected heterozygosity of clusters I, II and III were $0.672,0.787$ and 0.584, respectively (Fig. 3b). When $K=4$, cluster II from the $K=3$ analysis was divided into two clusters. The wild population at Site g was assigned to cluster II and the wild populations at Sites e and i were assigned to cluster III. The $F$ values of cluster I and IV were higher than those of cluster II and III, and the expected heterozygosity of cluster I, II, III and IV were 0.667, 0.744, 0.786 and 0.584, respectively (Fig. 3b). variation was described by the first two axes (Fig. 4). The specimens' seedlings and the wild individuals were plotted as a single group at Site d. On the other hand, the plots of specimens' seedlings at Sites e and g were nearby the wild individuals. The plots of seedlings at Site i were markedly removed from those of the wild individuals.

\section{Discussion}


262 We found that $18.4 \%$ of specimens' seeds were germinated. Furthermore, the specimens' seedlings

263 had unique alleles that did not exist in the wild populations, although the genetic diversity of germinated specimens' seedlings was lower than that of wild populations and clear genetic structure was observed between specimens’ seedlings and wild populations at the three sites. These result suggested that viable herbarium-specimen sourced seeds can contribute to the restoration of genetic diversity in threatened plants as ex situ conservation resources.

The specimens' seedlings from each site had one to three unique alleles (Table 2). Although we may have declined in recent decades. The specimens' seedlings probably had the alleles that had extirpated from current wild populations. Thus, the reintroduction of specimens' seedlings with these unique alleles would be useful to restore or augment the genetic diversity of the wild populations. specimens' seedlings was lower than that of the wild population. In this study, we used only one specimen fruit per population in order to minimize the damage to the specimens. Because the subfamily Asclepiadoideae of Apocynaceae is pollinated via transfer of pollinia, multiple paternities are very low within fruits (Broyles and Wyatt 1990; Wyatt and Broyles 1994). Therefore, the genetic diversity of the specimens' seedlings would be enhanced by using the seeds of (1) multiple fruits and specimens, (2) species that do not form pollinia (i.e. Orchidaceae and Asclepiadoideae) and allogamous species and (3) fruits from chasmogamous flowers. 
284 observed between the specimens' seedlings and the wild populations (Figs. 3 and 4). This could be

285 because the specimens' seedlings retained different alleles than the wild populations and they

286 exhibited low genetic diversity. Similarly, significant genetic differences between the seedlings

287 derived from soil seedbanks and the wild populations were also reported (Honnay et al. 2008).

288 Reintroduction of many seedlings taken from only a few specimens or fruits might lead to the

289 dominance of a few alleles in the wild populations. Thus, collecting seeds from multiple fruits and

290 specimens would enhance the genetic diversity of specimens' seedlings so that they more closely

291 resemble the original populations, and the allele frequencies of the seedlings would then be more

292 similar to the wild populations.

294 Usability of herbarium specimens' seeds of threatened plants

295 In this study, we determined that $18.4 \%$ of specimens’ seeds, which had been collected recently

296 (<19 years), were germinated. These germinated seeds preserved in herbarium could be useful in

297 reintroduction or augmentation resources because viable seeds and bulbils of plants can be preserved

298 for a long time (>20 years) under ideal conditions (Probert et al. 2009; Alsos et al. 2013). In addition,

299 seeds that possess physical dormancy and those with large embryos and little endosperm remain

300 viable for a longer time (Merritt et al. 2014). The seeds of V. pycnostelma also possess a

301 physiological dormancy and Vincetoxicum species have large embryos (Martin 1946; Zhou et al.

302 2003; Baskin and Baskin 2014). Thus, the seeds of V. pycnostelma specimens collected more than 20

303 years prior to the study would have a potential to germinate, although we used only nine fruits for

304 germination test in this study. Furthermore, 3.0\% of the ungerminated specimens' seeds that were

305 collected 9-18 years prior to the study were viable (Table 1). Because such seeds may be in a 
306 dormant state, seed dormancy should be broken using various methods such as cold stratification,

307 chemicals, heat shock, hormones or scarification (Fontaine et al. 1994; Susko et al. 2001; Kanmegne and Omokolo 2008; Baskin and Baskin 2014). To germinate seeds, it is important to create

309 appropriate environments for inducing germination based on the germination characteristics of the

310 target species. Zygotic embryo culture and callus culture technologies are also available for regenerating endangered plants (Gomes et al. 2003; Rambabu et al. 2006). These technologies could be used to increase the number of individuals derived from the specimens' seeds. The storage conditions in herbaria are also important for specimens’ seed longevity. Insect controls that avoid

314 heating, but employ nitrogen, argon, carbon dioxide and freezing have been developed in herbaria

315 (Strang 1992; Valentin 1993); these controls do not have negative effects on seed germination of many species (Bass and Stanwood 1978; Prokopiev et al. 2014).

317 It is recommended that sampling regimes for reintroduction resources should involve collecting 1 to 20 seeds per individual from each of 10 to 50 individuals belonging to each of five separate populations to remove the inbreeding depression (Falk and Holsinger 1991). Hoban and Schlarbaum

320 (2014) also suggest that we should collect seeds from 25 to 30 individuals belonging to the few but widely dispersed populations and between two to eight seeds of fruits per individual to maintain their genetic diversity. However, many specimens of target species collected from the same site ( $>10$ individuals) may be rarely preserved in a herbarium. In addition, damage to an excessive number of specimens should be minimized because museum specimens are very valuable and irreplaceable (Graves and Braun 1992; Wandeler et al. 2007; Shiga 2013). Furthermore, the number of retained and available seeds on herbarium specimens would be also not known before their germination tests. 
reintroduction resources. For example, it is feasible to sample across many sites and have wider genetic variation if material is sourced from several herbaria.

In recent decades, in addition to the designation of the sampling guidelines of seed banking projects, their utilization for ex situ conservation has been increasingly applied to a more diverse array of wild species (Schoen and Brown 2001; Van Slageren 2003; Guerrant et al. 2014; Hoban and Schlarbaum 2014). However, the application of seed banking projects may be difficult for the conservation of locally threatened populations because these projects usually do not assume the conservation of the local populations. The use of herbaria specimens' seeds would also remarkably contribute to restore the genetic diversity of not only the plant species but also each locally threatened population if the viable specimens' seeds collected at the target species or populations are preserved in herbaria.

\section{Acknowledgments}

We thank M. Azuma and M. Zushi for their helpful specimens’ seeds sampling support. This work was supported by Grants in Aid for Scientific Research (23701024, 26350387) from the Japan Society for the

Promotion of Science.

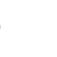




\section{References}

351 Aguilar R, Ashworth L, Galetto L, Aizen MA (2006) Plant reproductive susceptibility to habitat

352 fragmentation: review and synthesis through a meta-analysis. Ecol lett 9: 968-980

353 Alsos IG, Müller E, Eidesen PB (2013) Germinating seeds or bulbils in 87 of 113 tested Arctic species

354 indicate potential for ex situ seed bank storage. Pol Biol 36: 819-830

355 Baskin CC, Baskin JM (2014) Seeds: Ecology, Biogeography, and Evolution of Dormancy and Germination (Second Edition). Academic Press, San Diego

Bass LN, Stanwood PC (1978) Long-term preservation of sorghum seed as affected by seed moisture, temperature, and atmospheric environment. Crop Sci 18: 575-577

Becker U, Colling G, Dostal P, Jakobsson A, Matthies D (2006) Local adaptation in the monocarpic perennial Carlina vulgaris at different spatial scales across Europe. Oecologia 150: 506-518

Bewley JD, Bradford KJ, Hilhorst HWM, Nonogaki H (2013) Seeds: Physiology of Development, Germination and Dormancy, 3rd Edition. Springer, New York

Blows MW, Hoffmann AA (2005) A reassessment of genetic limits to evolutionary change. Ecology 86: $1371-1384$

Boutin-Ganache I, Raposo M, Raymond M, Deschepper CF (2001) M13-tailed primers improve the reliability and usability of microsatellite analyses performed with two different allele sizing methods.

Bowles ML, Betz RF, DeMauro MM (1993) Propagation of rare plants from historic seed collections:

Broyles SB, Wyatt R (1990) Paternity analysis in a natural population of Asclepias exaltata: multiple 
372 Ceballos G, Ehrlich PR (2002) Mammal population losses and the extinction crisis. Science 296: 904-907

373 Cottrell, HJ (1947) Tetrazolium salt as a seed germination indicator. Nature 159: 748

374 Earl DA, vonHoldt BM (2012) STRUCTURE HARVESTER: a website and program for visualizing

375 STRUCTURE output and implementing the Evanno method. Conserv Genet Res 4: 359-361

Elias SG, Copeland LO, McDonald MB, Baalbaki RZ (2012) Seed Testing: Principles and Practices.

El Mousadik EA, Petit RJ (1996) High level of genetic differentiation for allelic richness among

832-839

Environment Agency of Japan (2000) Threatened Wildlife of Japan - Red Data Book 2nd ed. Vascular 3.

Falk DA, Holsinger KE (1991) Genetics and conservation of rare plants. Oxford university press, New

Flora of Korea Editorial Committee (2007) The Genera of Vascular Plants of Korea. Academy Publishing, Seoul

Fontaine O, Huault C, Pavis N, Billard JP (1994) Dormancy breakate of Hordeum vulgare seeds: effects of hydrogen peroxide and scarification on glutathione level and glutathione reductase activity. Plant

Frankel OH, Soulé ME (1981) Conservation and Evolution. Cambridge University Press, Cambridge

Frankham R, Ballou JD, Briscoe DA (2009) Genetic management of captive populations. In: Introduction 
Goudet J (2001) FSTAT, a program to estimate and test gene diversities and fixation indices (version

Guerrant Jr EO, Havens,K, Vitt P (2014) Sampling for effective ex situ plant conservation. Int J Plant Sci 175: $11-20$

Hoban S, Schlarbaum S (2014) Optimal sampling of seeds from plant populations for ex-situ 99

Honnay O, Bossuyt B, Jacquemyn H, Shimono A, Uchiyama K (2008) Can a seed bank maintain the genetic variation in the above ground plant population? Oikos 117: 1-5

410 Naeem S, Schmid B, Setälä H, Symstad AJ, Vandermeer J, Wardle DA (2005) Effects of biodiversity

Hubisz MJ, Falush D, Stephens M, Pritchard JK (2009) Inferring weak population structure with the assistance of sample group information. Mol Ecol Resour 9: 1322-1332 
417 Kanmegne G, Omokolo ND (2008) Germination of Garcinia kola (Heckel) seeds in response to different 418 hormone treatments. Fruits 63: 155-161

419 Keller LF, Waller DM (2002) Inbreeding effects in wild populations. Trends Ecol Evolut 17: 230-241

Koyanagi TF. Furukawa T (2013) Nation-wide agrarian depopulation threatens semi-natural grassland species in Japan: Sub-national application of the Red List Index. Biol Conserv 167: 1-8

Leimu R, Fischer M (2008) A meta-analysis of local adaptation in plants. PLoS One 3: e4010

León-Lobos P, Way M, Aranda PD, Lima-Junior M (2012) The role of ex situ seed banks in the conservation of plant diversity and in ecological restoration in Latin America. Plant Ecol Divers 5: $245-258$

Lledó MD, Crespo MB, Amo-Marco JB (1996) Micropropagation of Limonium thiniense Erben

Magrini S (2011) Herbaria as useful spore banks for integrated conservation strategies of pteridophytic diversity. Plant Biosyst 145: 635-637

Magrini S, Olmati C, Onofri S, Scoppola A (2010) Recovery of viable germplasm from herbarium specimens of Osmunda regalis L. Amer. Fern J. 100: 159-166 old isolated butterfly population. Proc Natl Acad Sci 109: 2496-2505 
Milián-García Y, Venegas-Anaya M, Frias-Soler R, Crawford AJ, Ramos-Targarona R,

440 Rodríguez-Soberón R, Alonso-Tabet A, Thorbjarnarson J, Sanjur OI, Espinosa-López G, Bermingham

441 E (2011) Evolutionary history of Cuban crocodiles Crocodylus rhombifer and Crocodylus acutus

Milligan B (1992) Plant DNA isolation. In: Hoelzel AR (ed) Molecular Genetic Analysis of Populations: a

Ministry of the Environment Government of Japan (2012) The Red List of Vascular Plants of Japan.

Montalvo AM, Ellstrand NC (2001) Nonlocal transplantation and outbreeding depression in the subshrub Lotus scoparius (Fabaceae). Am J of Bot 88: 258-269

Nakahama N, Kaneko S, Hayano A, Isagi Y, Inoue-Murayama M, Tominaga T (2012) Development of microsatellite markers for the endangered grassland species Vincetoxicum pycnostelma (Apocynaceae),

Osaka Museum of Natural History (2012) Collecting and storage business. Annu Rep Osaka Mus Nat 
Probert RJ, Daws MI, Hay FR (2009) Ecological correlates of ex situ seed longevity: a comparative study on195 species. Ann Bot 104: 57-69

Prokopiev IA, Filippova GV, Shein AA (2014) Effect of different conditions of welsh onion seed storage

Qvenild M (2008) Svalbard Global Seed Vault: a ‘Noah's Ark’for the world's seeds. Dev Pract 18: 110_

Rambabu M, Upender M, Ujjwala D, Ugandhar T, Praveen M, Swamy NR (2006) In vitro zygotic embryo culture of an endangered forest tree Givotia rottleriformis and factors affecting its germination and seedling growth. In Vitro Cell Dev-Pl 42: 418-421

Schoen DJ, Brown AH (2001) The conservation of wild plant species in seed banks. Attention to both taxonomic coverage and population biology will improve the role of seed banks as conservation tools. Bioscience 51: 960-966 specimens: toward a better specimen preservation, collection and usage (Museum and ecology (22)). Jap J Ecol 63: 375-383 (in Japanese)

Smouse PE, Peakall R (1999) Spatial autocorrelation analysis of individual multiallele and multilocus

Strang TJK (1992) A review of published temperatures for the control of pest insects in museums. Collect Forum 8: 41-67 
482 Uematsu Y, Koga T, Mitsuhashi H, Ushimaru A (2010) Abandonment and intensified use of agricultural

483 land decrease habitats of rare herbs in semi-natural grasslands. Agricult Ecosys Environ 135: 304-309

484 Uesugi R, Nishihiro J, Tsumura Y, Washitani I (2007) Restoration of genetic diversity from soil seed

485 banks in a threatened aquatic plant, Nymphoides peltata. Conserv Genet 8: 111-121

486

Valentin N (1993) Comparative analysis of insect control by nitrogen, argon and carbon dioxide in museum, archive and herbarium collections. Int Biodeterior Biodegrad 32: 263-278

Van Slageren W (2003) The Millennium Seed Bank: building partnerships in arid regions for the conservation of wild species. J Arid Environ 54: 195-201

Washitani I (1987) A convenient screening test system and a model for thermal germination responses of

Wandeler P, Paquita EAB, Lukas FK (2007) Back to the future: museum specimens in population genetics.

TREE 22: 634-642

Willi Y, Van Buskirk J, Hoffmann AA (2006) Limits to the adaptive potential of small populations. Annu

Windham MD, Wolf PG, Ranker TA (1986) Factors affecting prolonged spore viability in herbarium

Wu ZY, Raven PH (1995) Flora of China. Vol. 16 (Gentianaceae through Boraginaceae). Science Press,

Wyatt R, Broyles S (1994) Ecology and evolution of reproduction in Milkweeds. Annu Rev Ecol Evol 25: 
504 Zaghloul M, Reisch C, Poschlod P (2013) Soil seed bank contributes significantly to genetic variation of

505 Hypericum sinaicum in a changing environment. Plant Syst Evol 299: 819-828

506 Zhou YF, Hang YZ, Zhou LL, Wang KC (2003) The germination characteristics of Cynanchum

507

paniculatum seeds. J Plant Resourc Environ 12: 35-38

508

509

510

511

512

513

514

515

516

517

518

519

520

521

522

523

524

525 


\section{Supplementary material}

527 Additional supplemental material can be found in the online version of this article.

528

529

Table S1 The condition of germination test

530

531

Figure S1 The $\Delta K$ in the STRUCTRE analysis

532

533

534

535

536

537

538

539

540

541

542

543

544

545

546

547 
548 Table 1 Specimen characteristics and number of seeds used in experiments

\begin{tabular}{|c|c|c|c|c|c|c|c|c|c|c|}
\hline \multirow[b]{2}{*}{ Site } & \multirow[b]{2}{*}{ Prefecture } & \multirow{2}{*}{$\begin{array}{l}\text { No. of } \\
\text { years } \\
\text { after } \\
\text { collected }\end{array}$} & \multirow[b]{2}{*}{$\begin{array}{l}\text { Date of } \\
\text { collecting } \\
\text { specimens }\end{array}$} & \multirow[b]{2}{*}{ Voucher specimen } & \multicolumn{3}{|c|}{ Increasing temperature condition } & \multicolumn{3}{|c|}{ decreasing temperature condition } \\
\hline & & & & & $\begin{array}{l}\text { No. of } \\
\text { seeds used } \\
\text { experiment }\end{array}$ & $\begin{array}{l}\text { No. of } \\
\text { germinated } \\
\text { seeds }\end{array}$ & $\begin{array}{l}\text { No. of viable } \\
\text { ungerminated } \\
\text { seeds }\end{array}$ & $\begin{array}{l}\text { No. of } \\
\text { seeds used } \\
\text { experiment }\end{array}$ & $\begin{array}{l}\text { No. of } \\
\text { germinated } \\
\text { seeds }\end{array}$ & $\begin{array}{l}\text { No. of viable } \\
\text { ungerminated } \\
\text { seeds }\end{array}$ \\
\hline $\mathrm{a}$ & Gifu & 16 & 25 Sep. 1997 & H. Marui 2434 (OSA203391) & 10 & 0 & 1 & 10 & 0 & 0 \\
\hline b & Kyoto & 51 & 16 Sep. 1962 & M. Hutoh 24248 (OSA214994) & 9 & 0 & 0 & 9 & 0 & 0 \\
\hline c & Kyoto & 22 & 24 Sep. 1991 & T. Fujii 2413 (OSA209484) & 10 & 0 & 0 & 10 & 0 & 0 \\
\hline d & Nara & 4 & 12 Oct. 2009 & S. Onoue s.n. (OSA225354) & 9 & 3 & 0 & 9 & 3 & 0 \\
\hline e & Nara & 16 & 03 Aug. 1997 & K. Seto 47673 (OSA104247) & 11 & 0 & 0 & 11 & 4 & 0 \\
\hline $\mathrm{f}$ & Nara & 62 & 03 Jul. 1951 & M. Hori s.n. (OSA190777) & 8 & 0 & 0 & 8 & 0 & 0 \\
\hline g & Osaka & 3 & 26 Nov. 2010 & F. Uwakubo 101126-002 (OSA185864) & 12 & 0 & 0 & 12 & 2 & 0 \\
\hline h & Osaka & 9 & 10 Oct. 2004 & K. Hirano 2501 (OSA280257) & 11 & 0 & 2 & 11 & 0 & 0 \\
\hline \multirow[t]{2}{*}{$\mathrm{i}$} & Hyogo & 18 & 02 Nov. 1994 & S. Miyake 2987 (OSA122127) & 23 & 16 & 2 & 23 & 10 & 0 \\
\hline & & & & Total & 103 & 19 & 5 & 103 & 19 & 0 \\
\hline
\end{tabular}


551 Table 2 Genetic diversity measurements of each site of Vincetoxicum pycnostelma. Each site contained specimens' seedlings, a wild and a

hypothetical mixed population (specimens' seedlings + wild population). $A$, numbers of alleles per locus; $A R$, allelic richness; $R A$, summed number of rare alleles; $U A$, summed number of unique alleles that are only present in specimens' seedlings; $H_{\mathrm{O}}$, observed heterozygosity (in bold numbers, if values are significantly deviated from HWE); $H_{\mathrm{E}}$, expected heterozygosity; $F_{\mathrm{IS}}$, inbreeding coefficient

\begin{tabular}{|c|c|c|c|c|c|c|c|c|c|c|}
\hline Site & Wild Population size & Sample & No. of samples & $A$ & $A R$ & $R A$ & $U A$ & $H_{\mathrm{O}}$ & $H_{\mathrm{E}}$ & $F_{\text {IS }}$ \\
\hline \multirow{3}{*}{$\mathrm{d}$} & \multirow[b]{3}{*}{20} & specimens' seedlings & 6 & 3.111 & 2.366 & 5 & 0 & 0.815 & 0.582 & -0.382 \\
\hline & & Wild population & 19 & 6.222 & 2.683 & 17 & & 0.754 & 0.687 & -0.106 \\
\hline & & $\begin{array}{l}\text { Hypothetical mixed } \\
\text { population }\end{array}$ & 25 & 6.222 & 2.637 & 17 & & 0.769 & 0.680 & -0.137 \\
\hline \multirow{3}{*}{ e } & \multirow{3}{*}{$220 *$} & specimens' seedlings & 4 & 3.000 & 2.406 & 5 & 1 & 0.778 & 0.566 & -0.348 \\
\hline & & Wild population & $46 *$ & 11.333 & 2.917 & 51 & & 0.749 & 0.752 & 0.008 \\
\hline & & $\begin{array}{l}\text { Hypothetical mixed } \\
\text { population }\end{array}$ & 50 & 11.444 & 2.929 & 52 & & 0.751 & 0.756 & 0.010 \\
\hline \multirow{3}{*}{ g } & \multirow[b]{3}{*}{100} & specimens' seedlings & 2 & 2.222 & 2.222 & 2 & 1 & 0.833 & 0.472 & -0.767 \\
\hline & & Wild population & 50 & 10.000 & 2.859 & 39 & & 0.767 & 0.748 & -0.030 \\
\hline & & $\begin{array}{l}\text { Hypothetical mixed } \\
\text { population }\end{array}$ & 52 & 10.111 & 2.858 & 40 & & 0.769 & 0.748 & -0.034 \\
\hline \multirow{2}{*}{$\mathrm{i}$} & \multirow[b]{2}{*}{24} & specimens' seedlings & 20 & 2.889 & 2.230 & 3 & 3 & 0.694 & 0.570 & -0.205 \\
\hline & & $\begin{array}{l}\text { Hypothetical mixed } \\
\text { population }\end{array}$ & 36 & 8.000 & 2.765 & 27 & & 0.698 & 0.725 & 0.044 \\
\hline
\end{tabular}


Fig. 1 a The herbarium specimen of Vincetoxicum pycnostelma collected site i (OSA122127). Arrow head indicates the fruit, Bar indicates 50mm. b Seeds in the fruits of OSA122127. Bar indicates 5.0mm. c

Fig. 2 a Locations of the collected Vincetoxicum pycnostelma specimens in Kinki and Tokai districts. b

Location of Kinki and Tokai districts in Japan

Fig. 3 Results of Bayesian clustering in the STRUCTURE analysis (Pritchard et al. 2010). a The each of the inferred clusters for $K=2$. $\mathbf{b}$ The proportion of the membership coefficient of 163 individuals in the specimens' seedlings and wild populations at the four sites (right side: specimens' seedlings, left side: wild populations) for each of the inferred clusters for $K=3$ and $K=4$. Each column represents an individual

Fig. 4 Principal coordinates analysis plots of individuals at the four sites (each contains specimens' seedlings and wild populations) based on co-dominant genotypic distances (Smouse and Peakall 1999). 
Figure 1

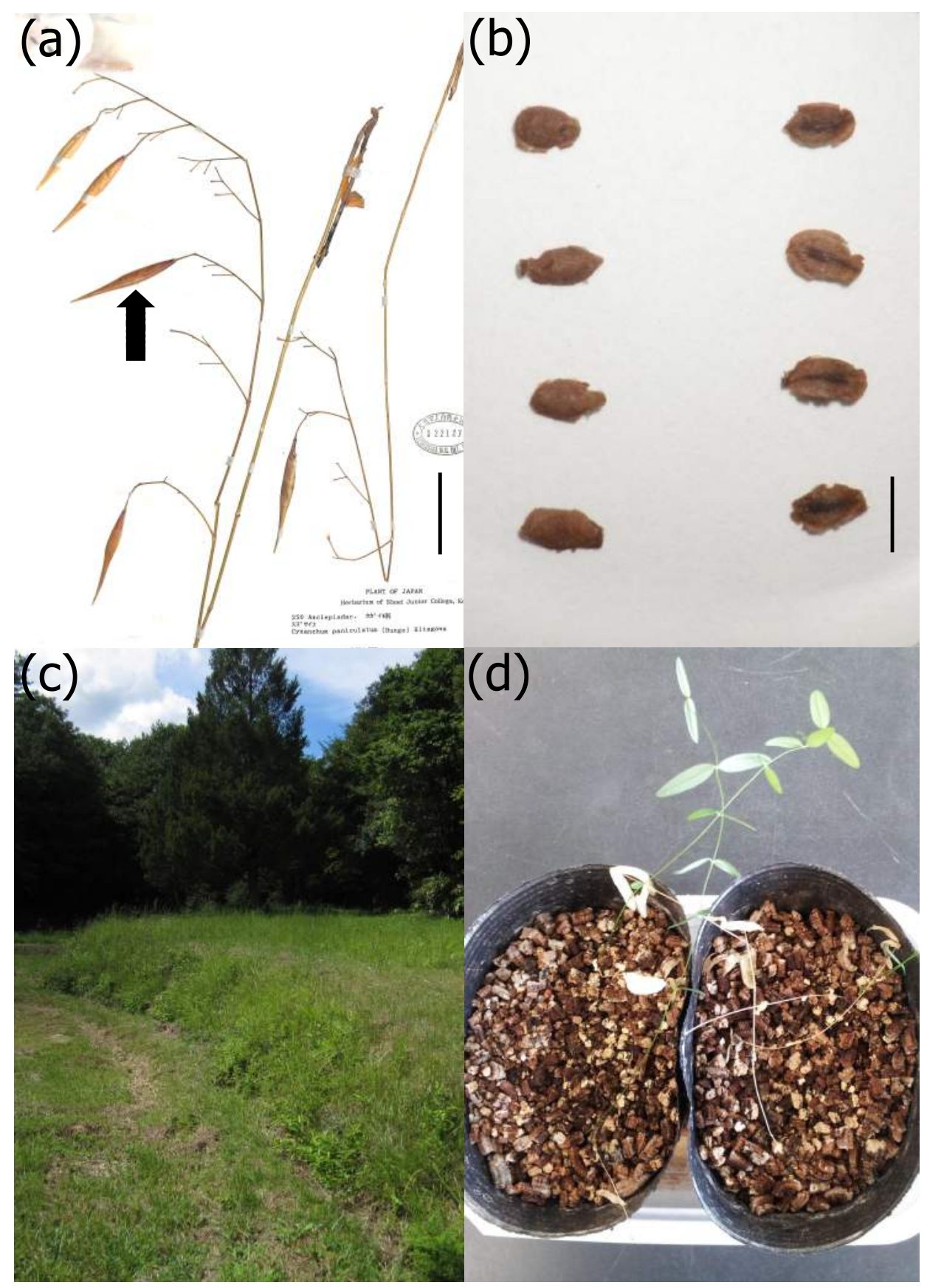


Figure 2

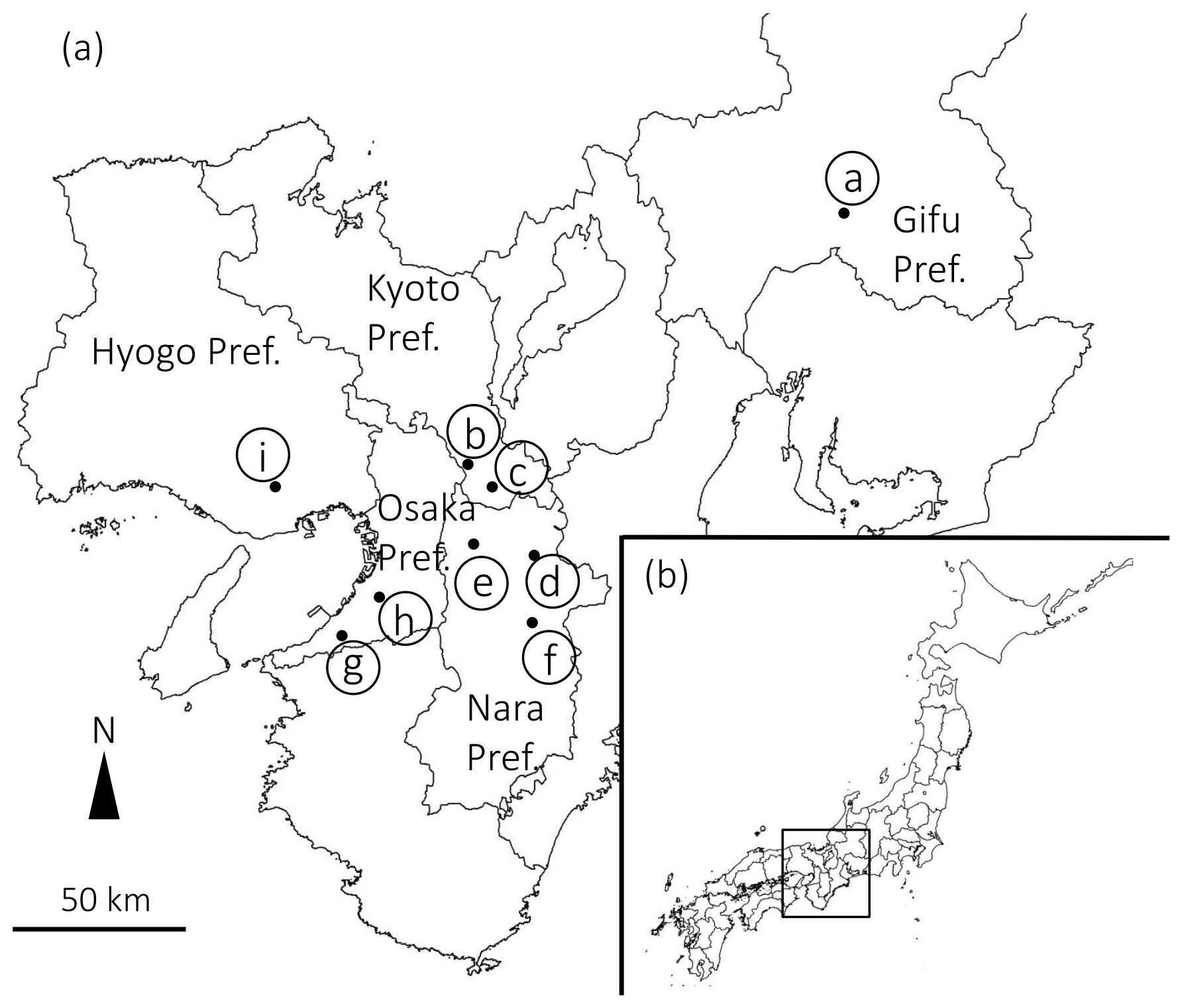


Figure 3

(a) $\mathrm{d}$

e

g

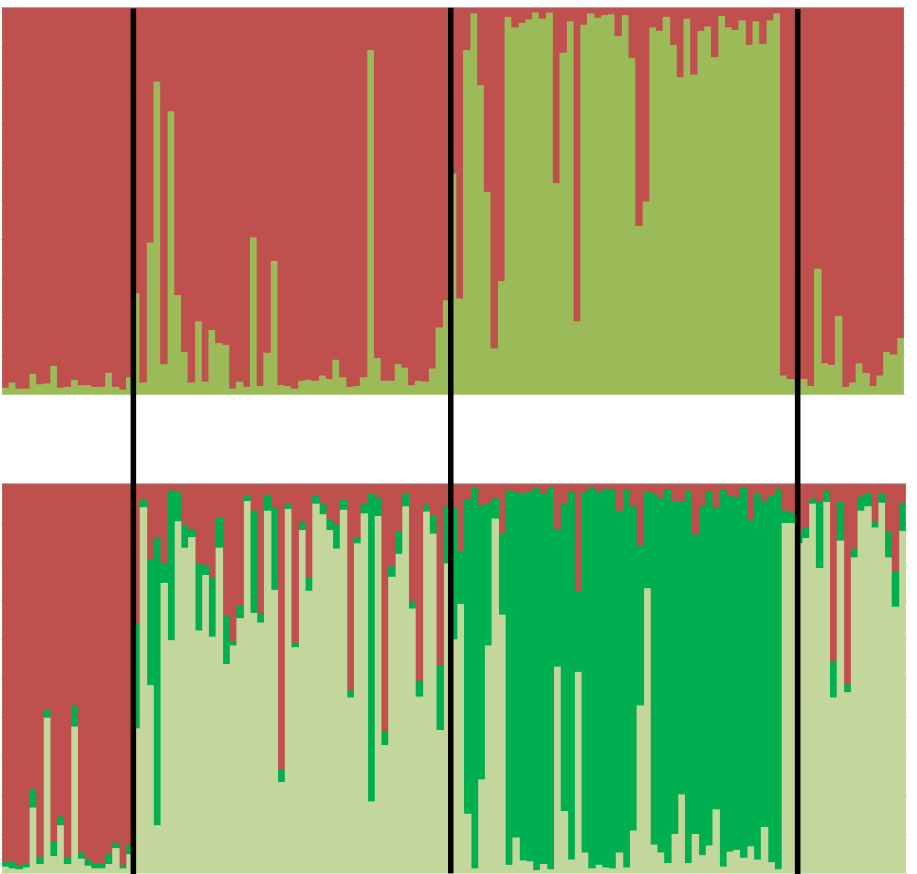

Cluster I

$F=0.012 \quad H_{E}=0.780$

Cluster II

$F=0.082 \quad H_{E}=0.747$

Cluster I

$\mathrm{F}=0.094 \quad \mathrm{H}_{\mathrm{E}}=0.743$

Cluster II

$F=0.094 \quad H_{E}=0.742$

Cluster III

$F=0.008 \quad H_{E}=0.781$

(b)

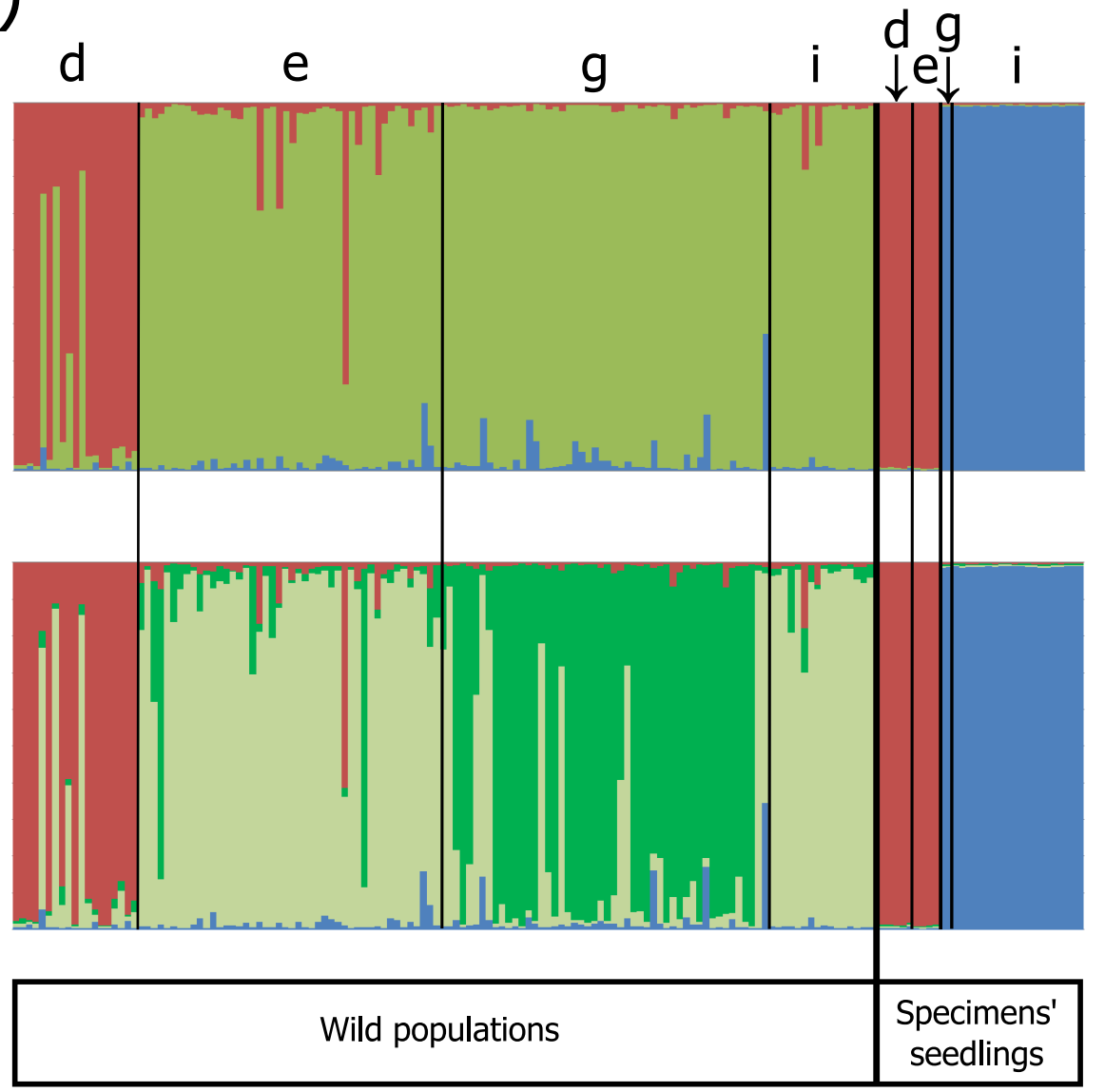

Cluster I

$F=0.234 \quad H_{E}=0.672$

Cluster II

$\mathrm{F}=0.000 \quad \mathrm{H}_{\mathrm{E}}=0.787$

Cluster III

$F=0.489 \quad H_{E}=0.584$

Cluster I

$F=0.238 \quad H_{E}=0.667$

Cluster II

$\mathrm{F}=0.086 \quad \mathrm{H}_{\mathrm{E}}=0.744$

Cluster III

$\mathrm{F}=0.000 \quad \mathrm{H}_{\mathrm{E}}=0.786$

Cluster IV

$F=0.495 \quad H_{E}=0.584$ 
Figure 4

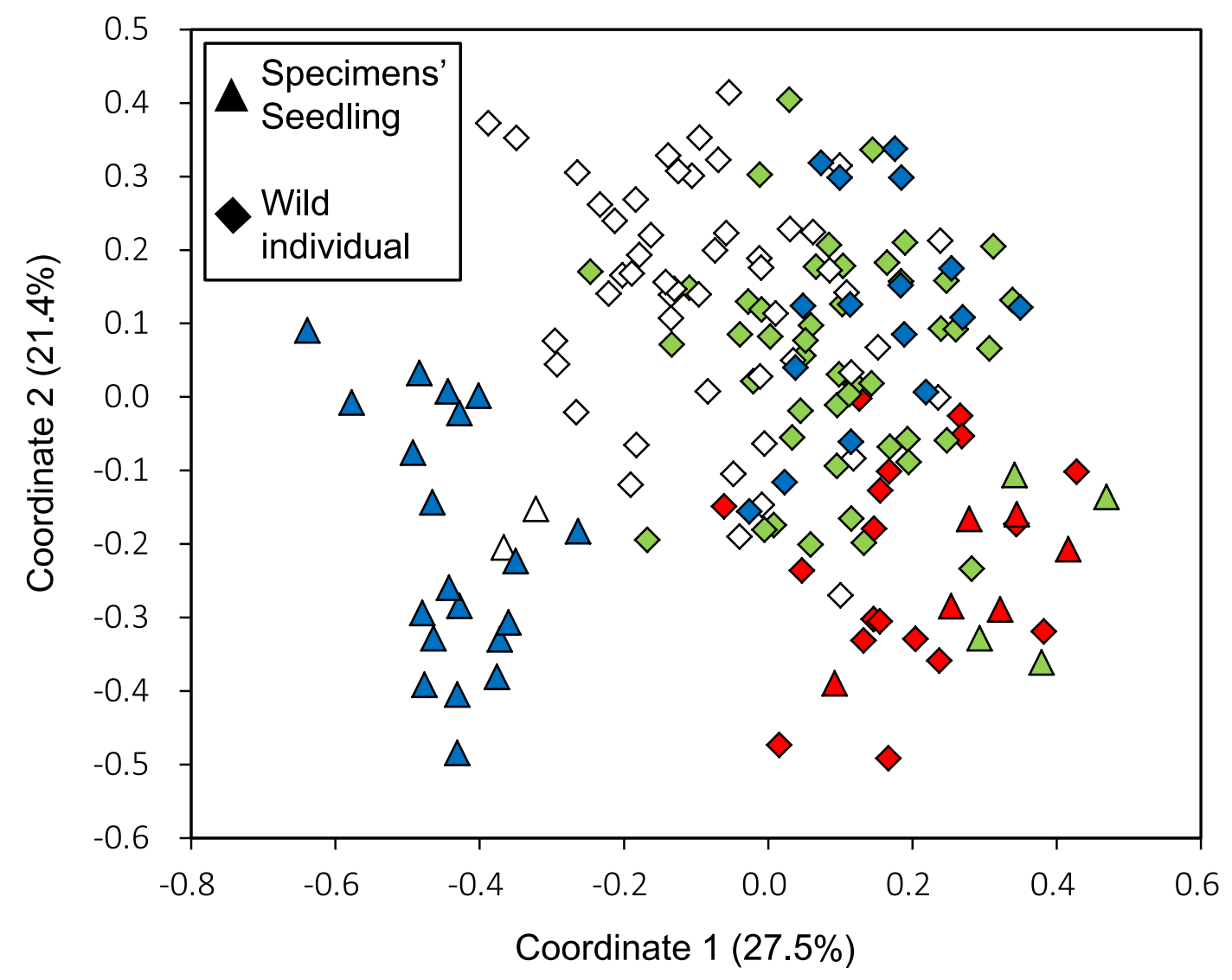


1 Table S1 Relationships between temperature and number of days in each condition. In the increasing temperature condition, the temperature was 2 alternated between 12 and $25^{\circ} \mathrm{C}$ in 24 -h intervals after arriving at the final temperature

\begin{tabular}{|c|c|c|c|c|c|c|c|c|c|c|c|}
\hline \multirow{2}{*}{$\begin{array}{l}\text { Increasing } \\
\text { temperature } \\
\text { condition }\end{array}$} & Temperature $\left({ }^{\circ} \mathrm{C}\right)$ & 4 & 8 & 12 & 16 & 20 & 24 & 28 & 32 & 36 & $12 \sim 25$ \\
\hline & Number of days & 8 & 5 & 4 & 3 & 2 & 2 & 2 & 2 & 2 & 5 \\
\hline \multirow{2}{*}{$\begin{array}{l}\text { Decreasing } \\
\text { temperature } \\
\text { condition }\end{array}$} & Temperature $\left({ }^{\circ} \mathrm{C}\right)$ & 36 & 32 & 28 & 24 & 20 & 16 & 12 & 8 & 4 & 25 \\
\hline & Number of days & 2 & 2 & 2 & 2 & 2 & 3 & 4 & 5 & 8 & 5 \\
\hline
\end{tabular}

3
4
5
6
7




\section{Figure $\mathbf{S 1}$}

9 The $\Delta K$ in the STRUCTRE analysis based on the rate of change in the log probability of data between 10 successive $K$ values (Evanno et al. 2005). (a) The result of 131 individuals in the only wild populations of 11 the four sites. (b) The result of 163 individuals in the specimens' seedlings and wild populations of four 12 sites.

(a)

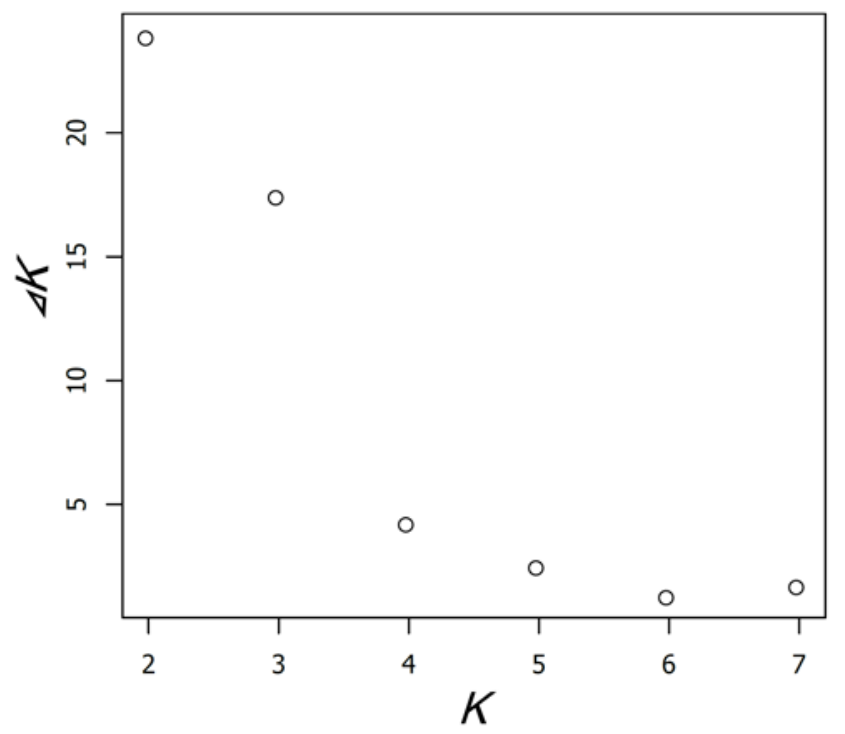

(b)

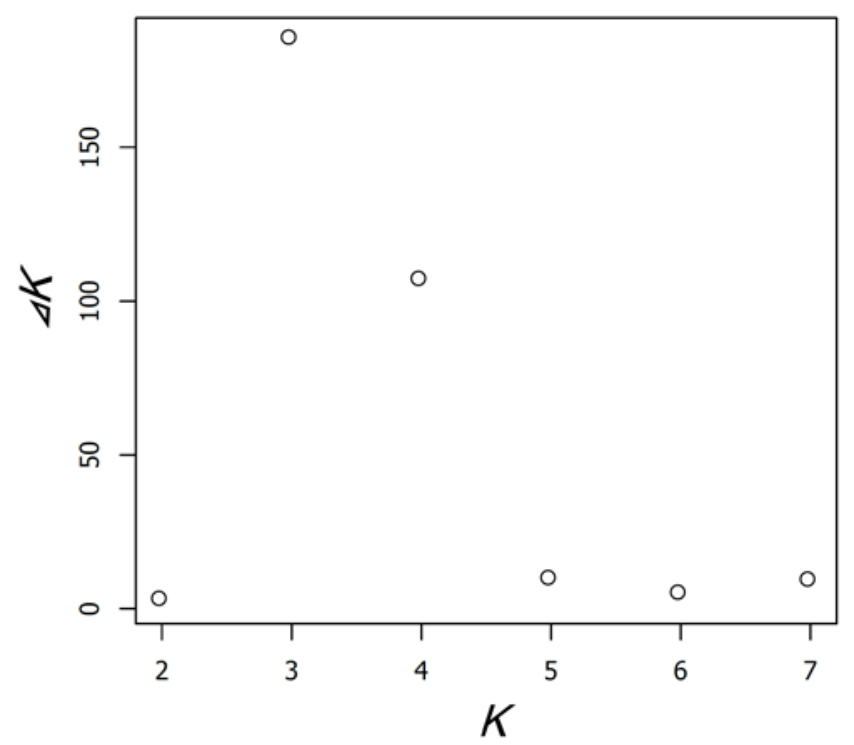

uv

37

References

Evanno G, Regnaut S, Goudet J (2005) Detecting the number of clusters of individuals using the software Structure: a simulation study. Mol Ecol 14: 2611-2620 